This article is licensed under the Creative Commons Attribution-NonCommercial 4.0 International License (CC BY-NC) (http://www.karger.com/Services/OpenAccessLicense). Usage and distribution for commercial purposes requires written permission.

\title{
Surgical Treatment following Chemo-Targeted Therapy with Bevacizumab for Lung Metastasis from Colorectal Carcinoma: Analysis of Safety and Histological Therapeutic Effects in Patients Treated at a Single Institution
}

Tomoyuki Nakagiri $^{\mathrm{a}}$ Toshiteru Tokunaga ${ }^{\mathrm{a}}$ Hidenori Kunoh $^{\mathrm{a}}$ Shingo Noura ${ }^{b}$ Hiroto Ishida ${ }^{a}$ Norikatsu Miyoshi ${ }^{b}$ Masayuki Ohue ${ }^{b}$ Jiro Okami ${ }^{a}$ Masahiko Higashiyama ${ }^{a}$

${ }^{a}$ Department of Thoracic Surgery, Osaka International Cancer Institute (formerly Osaka Medical Cancer Center for Cancer and Cardiovascular Diseases), Osaka, Japan; ${ }^{b}$ Department of Surgery, Osaka International Cancer Institute (formerly Osaka Medical Cancer Center for Cancer and Cardiovascular Diseases), Osaka, Japan

\section{Keywords}

Lung metastasis · Colorectal carcinoma - Surgical treatment $\cdot$ Safety $\cdot$ Chemo-targeted therapy · Histological result

\section{Abstract}

Background: Recently, therapeutic strategies for a metastasectomy from colorectal carcinoma after chemo-targeted therapy with bevacizumab have been presented, with which some uncommon but serious adverse events have been reported. However, only few reports have investigated the safety of lung resection after such therapy or the histological effects. We 


\section{Case Reports in Oncology}

Case Rep Oncol 2018;11:98-108

DOI: $10.1159 / 000486825$

(C) 2018 The Author(s). Published by S. Karger AG, Base www.karger.com/cro

Nakagiri et al.: Surgical Treatment following Chemo-Targeted Therapy with Bevacizumab for Lung Metastasis from Colorectal Carcinoma

retrospectively analyzed the both of them at our institute. Methods: Of 69 colorectal carcinoma patients who underwent pulmonary metastasectomy procedures from 2009 to 2014, we investigated 11 who also received chemo-targeted therapy prior to surgery. Results: In addition to bevacizumab, 5 fluorouracil (FU)/leucovorin + oxaliplatin or capecitabine was given in 6 cases and $5 \mathrm{FU} /$ leucovorin + irinotecan in 5 cases. The mean period from the end of chemo-targeted therapy to surgery was $2.7 \pm 0.9$ months. The response to therapy shown in imaging findings was progressive disease in 6 , stable disease in 3, and partial response in 2 (response rate, 18.2\%). The operation modes were wedge resection $(n=8,72.3 \%)$, segmentectomy ( $n=2,1$ in bilateral lobes, 1 in the right lobe, 18.2\%), and lobectomy ( $n=1$, left lower lobectomy, 9.1\%). All patients safely underwent a complete resection. As for postsurgical complications, chylothorax occurred in 1 case and prolonged pulmonary air leakage in 1 case. The histological effects of chemo-targeted therapy were slight. There was no relationship between histological findings with imaging findings obtained prior to the operation ( $p=$ 0.63). The 5-year disease-free survival rate after metastasectomy was $10.9 \%$. Conclusions: Pulmonary metastasectomy after chemo-targeted therapy for colorectal carcinoma patients obtained acceptable results. In addition, there was no correlation between imaging and histopathologic results following chemo-targeted therapy.

(C) 2018 The Author(s)

Published by S. Karger AG, Basel

\section{Introduction}

Therapeutic strategies for colorectal carcinoma are generally based on surgical resection, as established guidelines recommend that or include it as a therapeutic option if the lesions are resectable, even in cases of stage IV colorectal carcinoma or recurrent tumors [1]. Patients who undergo a pulmonary metastasectomy for colorectal carcinoma have also been shown to have acceptable prognosis [2]. For lung metastasis, the 5-year overall survival rate following surgical resection is significantly better than that of patients without surgical resection (46.7 vs. $3.9 \%, p<0.0001$ ) [3]. On the other hand, there are several chemotherapy strategies with targeted therapy available, while the number of chemotherapy treatments has been increasing up to third- and fourth-line in some cases [1]. Based on the treatment outcome of surgical resection for patients with a remaining tumor and/or new lesions who underwent chemotherapy, surgical resection following chemo-targeted therapy is a viable therapeutic strategy. However, a previous report presented that there could be 2 uncommon but serious adverse events with targeted therapy: arterial thromboembolic events and gastrointestinal perforation [4].

Although the number of such patients may be increasing, there are few reports on the safety of a lung resection procedure after chemo-targeted therapy or the histological effects of such therapy. In the present study, we retrospectively analyzed the perioperative safety of patients who underwent a lung resection procedure after completing chemo-targeted therapy as the primary purpose as well as the differences between imaging and pathological results. 


\section{Case Reports in Oncology}

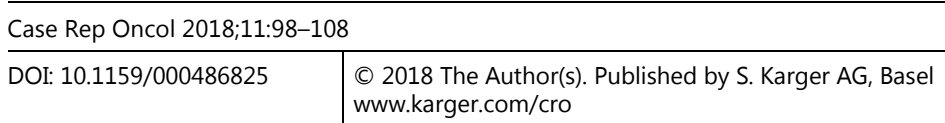

Nakagiri et al:: Surgical Treatment following Chemo-Targeted Therapy with Bevacizumab for Lung Metastasis from Colorectal Carcinoma

\section{Patients and Methods}

From 2009 to 2014, we performed 69 lung resection procedures for metastatic tumors originating from colorectal carcinoma at our institution. Of those, 11 (2 males, 18.2\%) treated with chemo-targeted therapy using bevacizumab (Avastin ${ }^{\circledR}$ ) before surgery were analyzed. The strategies for surgical therapy to treat patients with advanced and/or recurrent colorectal carcinoma after targeted chemotherapy at our institution are induction therapy, performed for patients expected to undergo an operation after finishing chemotherapy, and others. Other strategies are further divided into salvage therapy, which is occasionally performed when chemotherapy reduces the tumors to an operable size and/or number, and resection, which is performed for new lesions that appear soon after chemotherapy has finished. The present analysis included consecutively treated patients ( 5 induction therapy, 6 salvage therapy or resection for new lesions), each of whom underwent chemo-targeted therapy along with the aforementioned strategies just prior to surgery.

\section{Methods}

This was a retrospective study. As preoperative factors, we noted chemo-targeted therapy treatment, treatment effect shown in computed tomography findings, side effects, and the period from the end of treatment to the operation. The Common Terminology Criteria for Adverse Events (CTCAE) version 4.02 was used to evaluate side effects [5], while for treatment effect, Response Evaluation Criteria in Solid Tumors (RECIST) version 1.1 was utilized [6].

In addition, operation mode and time as well as blood loss were included as operative factors. As for postoperative factors, we examined the histological effects of chemo-targeted therapy, hospital stay, complications, and disease-free survival rate. For evaluation of the histopathological effects of treatment, we used a 4-point system reported in 2009 by the Japanese Society for Cancer of the Colon and Rectum [7]. Briefly, the classification is separated into 4 main categories and 2 subcategories based on cells obtained from remaining carcinoma tumors (online supplemental Table 1, see www.karger.com/doi/ $10.1159 / 000486825)$.

\section{Statistical Analysis}

Kaplan-Meier analysis and a log-rank test were used for survival curves and their comparisons, respectively. Values of $p \leq 0.05$ were considered to be significant.

\section{Results}

Patients

One patient had lung metastasis at the time of colorectal resection. The primary site of metastasis was the rectum $(n=8,72.7 \%)$, with the majority of those cases in the lower rectum (Rb; $n=6,54.5 \%$ of all cases). The mean pretherapeutic disease-free survival period was 22.5 months (range $0-58$ months) (Table 1 , Table 2). 
Chemotherapy and Effects

For first-line treatment, 5-fluorouracil/leucovorin (5 FU/LV) + oxaliplatin (FOLFOX) or capecitabine (CapeOX therapy) was used. In addition, bevacizumab was combined with firstline chemotherapy in 6 cases (54.5\%), while the remaining 5 patients, who underwent firstline chemotherapy without targeted therapy, received second-line chemotherapy with bevacizumab. As a result, all 11 patients received bevacizumab therapy just prior to surgery. The main overall response to chemotherapy shown in imaging findings was progressive disease (PD, $n=6$ ), while the others showed stable disease (SD, $n=3$ ) or partial response (PR, $n=2$; response rate $18.2 \%$ ) (Table 1 , Table 2).

\section{Preoperative Management and Indications}

The period from the end of chemo-targeted therapy to the operation was $2.7 \pm 0.9$ months. Chemotherapy-related data obtained just prior to the operation were nearly normalized in all patients. The overall rate of adverse events was decreased and grade improved from 2 to 1 in each case. None of the patients had Grade 3/4 side effects from chemo-targeted therapy during the preoperative period.

\section{Operation Results}

The operation mode in the majority of cases was wedge resection $(n=8,72.3 \%$; right lobe 3 , left lobe 3 , bilateral 2). Of the remaining patients, 2 underwent a segmentectomy (bilateral, right lobe) and 1 a lobectomy (left lower lobectomy). The median operation time was $75 \mathrm{~min}$ (53-180 min) and blood loss was slight (median $10 \mathrm{~mL}, 5-230 \mathrm{~mL}$ ), with the largest amount of blood loss noted in the patient who underwent a bilateral segmentectomy. The median hospital stay was 8 days (5-23 days), with the longest hospital stay noted in the patient who had chylothorax after the lobectomy. All patients underwent a complete resection. Following the operation, there was $1(9.1 \%)$ case of chylothorax and $1(9.1 \%)$ case of prolonged pulmonary air leakage (Table 2, Table 3). There was no significant difference in regard to the period from the end of chemo-targeted therapy to the operation between patients with and those without complications $(2.1 \pm 1.2$ vs. $2.9 \pm 1.2$ months, $p=0.16)$.

\section{Postoperative Courses}

The 5-year disease-free survival rate after lung resection was $10.9 \%$. Tumor recurrence was observed in 9 patients (81.8\%), while brain metastasis was observed in 4, lung metastasis in 2 , and multiple organ metastasis in 3 (Table 2).

\section{Histological Effects}

The histological effect of chemotherapy in each patient was primarily classified as Grade 1a $(n=9,81.8 \%)$ (Table 2, Table 3), while the remaining $(n=2)$ were evaluated as Grade $1 \mathrm{~b}$. In a comparison of histological results with imaging findings following chemo-targeted therapy among patients classified as Grade 1a, 5 showed PD, 2 SD, and 2 PR. On the other hand, in patients classified as Grade $1 \mathrm{~b}, 1$ showed PD and 1 SD $(p=0.63)$. The 2 patients with PR underwent the operation earlier after chemo-targeted therapy as compared to the Grade $1 \mathrm{~b}$ patients ( 2 and 1.2 months vs. 3.3 and 3.8 months, respectively) and their histological results classification was Grade 1a. In addition, the period from the end of chemo-targeted therapy 


\section{Case Reports in Oncology}

to the operation for Grade 1a patients was $2.5 \pm 0.9$ months $(1.2-3.7$ months), while it was $3.5 \pm 0.4$ months (3.3-3.8 months) for the Grade $1 \mathrm{~b}$ patients $(p=0.03)$.

\section{Representative Case}

\section{Case 1}

A 51-year-old man underwent a lower anterior resection for an Rs rectum carcinoma at the age of 46 years. The tumor was $2 \times 2 \mathrm{~cm}$ in size, type 2, mp, ly1, v1, N1 pStage IIIA. Following the operation, he was administrated tegafur-uracil (UFT) for 1 year. However, lung metastasis was found at 4.5 years after the operation and he was referred to our hospital. We noted a pulmonary tumor in the right lower lobe, $2 \mathrm{~cm}$ in size, with a maximum standardized uptake value (SUVmax) of 5.1 shown in positron emission tomography (PET) findings (Fig. 1). He then underwent CapeOX with bevacizumab therapy and computed tomography findings showed PR. After finishing chemotherapy, SUVmax was 2.3 (Fig. 2). At 2 months after the end of chemotherapy, the patient underwent a wedge resection of the right lower lobe and the histological response of the tumor was classified as Grade 1a.

\section{Discussion}

The lung is the second most common site of metastasis from colorectal carcinoma (8$18 \%$ ) [6], following only liver metastasis [8]. There are several options for chemotherapy performed in patients with unresectable colorectal carcinoma [1]. Following administration of FOLFOX and $5 \mathrm{FU} / \mathrm{LV}+$ irinotecan (FOLFIRI) therapy, the median survival of patients with advanced and/or recurrent colorectal carcinoma is longer than 20 months [9]; thus, that has become the most commonly used protocol for colorectal carcinoma. In addition, the median survival period after undergoing bevacizumab therapy is 4.7 months longer than that following other treatments for colorectal carcinoma [10]. Thus, the Japanese Society for Cancer of the Colon and Rectum recommends regimens that include a molecular targeting drug as standard therapy [1].

All of the present patients were administrated bevacizumab. As for its safety, previous studies have reported that colorectal surgery was safely performed more than 60 days after the final administration [11]. In a study of lung carcinoma cases, Chaft et al. [12] reported that the rate of surgical complication morbidity after bevacizumab treatment including neoadjuvant therapy was comparable to a previous study of patients who did not receive bevacizumab. However, they also reported 1 treatment-related death and that Grade 3 or 4 neutropenia occurred in 15 patients, which was relatively high as compared to those patients who did not receive bevacizumab. In our pulmonary metastasectomy cases, even though the period from the end of chemo-targeted therapy to the operation was less than 60 days in some, the rate of blood complications prior to the operation from end of the chemotherapy period to the preoperative period was decreased. As noted in previous studies [12], there were no perioperative thromboembolic events or wound-healing problems observed in our cohort. Unfortunately, following the operation, 1 patient $(9.1 \%)$ developed chylothorax and $1(9.1 \%)$ had prolonged pulmonary air leakage ( $>7$ days). The rate of chylothorax was higher and that of prolonged pulmonary air leakage lower than noted in previous re- 
ports (chylothorax: $0.2-2.6 \%$ [13], prolonged pulmonary air leakage: 15-18\% [14]). However, none of our patients required a reoperation or developed lethal complications. In addition, there was no difference in regard to the period from the end of chemo-targeted therapy to the operation between patients with and those without complications. One difference between previously reported lung cancer operations and those in the present study may have been the operation mode, as that in previous reports was mainly a lobectomy [12], whereas the present patients primarily underwent a wedge resection. In addition, the longest hospital stay and largest amount of blood loss in our cohort were noted in patients who underwent a segmentectomy procedure. Thus, we concluded that a lung wedge resection procedure can be safely performed for pulmonary metastasis following chemo-targeted therapy.

Previous studies have shown that chemo-targeted therapy is effective for colorectal carcinoma and prolongs overall survival [11]. Then, is surgical resection no longer necessary, or its necessity decreased? The histopathological effects of chemo-targeted therapy in the present cohort were not impressive, as illustrated by the results presented for the representative case.

Previous studies have found that PET is useful for evaluation of the effects of chemotargeted therapy [15]. Unfortunately, we used PET for examining the effects of chemotargeted therapy and lung resection in only 1 of the present patients, whose results are presented as representative Case 1 . In that patient, adjuvant chemo-targeted therapy showed a significant effect in PET findings. However, histopathological results revealed that tumor cells had survived (Grade 1a). In addition, though the period from the end of chemo-targeted therapy to the operation in the Grade $1 \mathrm{~b}$ group was longer as compared to that of the patients in the Grade 1a group, the histological effect was superior. Furthermore, even though that period was shorter in patients with PR as compared to the group with Grade 1b, their histological evaluation findings were worse. Finally, none of the histological results demonstrated a relationship with imaging findings. Together, these results suggest that it is difficult to accurately evaluate the effects of chemo-targeted therapy.

After taking into account our finding of no differences regarding the period from the end of chemo-targeted therapy to the operation between patients with and those without complications, we consider that it may be important to resect tumors as soon as possible after concluding chemo-targeted therapy, even for patients evaluated as PR based on imaging results. Furthermore, we concluded that the impact of surgical resection is considerable for pulmonary metastasis from colorectal cancer.

In conclusion, though some of our patients had complications, chemo-targeted therapy for lung metastasis from colorectal carcinoma was shown to be acceptable prior to surgical resection. In addition, there was no correlation between the effects of chemo-targeted therapy shown by imaging and its histological effects. Nevertheless, to more fully investigate the effects of a lung metastasectomy procedure after chemo-targeted therapy, accumulation of related reports and studies with a larger cohort are needed.

\section{Limitations}

The present cohort was composed of patients who came to us for tumor resection because of a remaining tumor. Thus, for most the effect of chemotherapy was PD rather than 
remission (CR, PR). In addition, all had surgically resectable tumors and an operable general status.

\section{Statements of Ethics}

Written informed consent for research and data sharing was obtained from all patients. This study was approved by the Ethics Committee of the Osaka Medical Center for Cancer and Cardiovascular Diseases (Approval No. 1302195141).

\section{Disclosure Statement}

The authors declare no conflict of interest associated with this paper.

\section{References}

1 Watanabe T, Itabashi M, Shimada Y, Tanaka S, Ito Y, Ajioka Y et al; Japanese Society for Cancer of the Colon and Rectum. Japanese Society for Cancer of the Colon and Rectum (JSCCR) Guidelines 2014 for treatment of colorectal cancer. Int J Clin Oncol. 2015 Apr;20(2):207-39.

2 Higashiyama M, Kodama K, Higaki N, Takami K, Murata K, Kameyama M et al. Surgery for pulmonary metastases from colorectal cancer: the importance of prethoracotomy serum carcinoembryonic antigen as an indicator of prognosis. Jpn J Thorac Cardiovasc Surg. 2003 Jul;51(7):289-96.

3 Hirosawa T, Itabashi M, Ohnuki T, Yamaguchi N, Sugihara K, Kameoka S; Japanese Society for Cancer of the Colon and Rectum (JSCCR) Study Group for Pulmonary Metastases from Colorectal Cancer. Prognostic factors in patients undergoing complete resection of pulmonary metastases of colorectal cancer: a multiinstitutional cumulative follow-up study. Surg Today. 2013 May;43(5):494-9.

4 Hurwitz H, Saini S. Bevacizumab in the treatment of metastatic colorectal cancer: safety profile and management of adverse events. Semin Oncol. 2006 Oct;33(5 Suppl 10):S26-34.

5 The National Cancer Institute [Internet]. Common Terminology Criteria for Adverse Events (CTCAE). Version 4.02 [published May 28, 2009]. Available from: http://evs.nci.nih.gov/ftp1/CTCAE/Archive/CTCAE_4.02_2009-09-15_QuickReference_8.5x11.pdf.

6 Eisenhauer EA, Therasse P, Bogaerts J, Schwartz LH, Sargent D, Ford R et al. New response evaluation criteria in solid tumours: revised RECIST guideline (version 1.1). Eur J Cancer. 2009 Jan;45(2):228-47.

7 General rules for clinical and pathological studies on cancer of the colon, rectum and anus. Part II. Histopathological classification. Japanese Research Society for Cancer of the Colon and Rectum. Jpn J Surg. 1983 Nov;13(6):574-98.

8 Hammoud MA, McCutcheon IE, Elsouki R, Schoppa D, Patt YZ. Colorectal carcinoma and brain metastasis: distribution, treatment, and survival. Ann Surg Oncol. 1996 Sep;3(5):453-63.

9 Tournigand C, André T, Achille E, Lledo G, Flesh M, Mery-Mignard D et al. FOLFIRI followed by FOLFOX6 or the reverse sequence in advanced colorectal cancer: a randomized GERCOR study. J Clin Oncol. 2004 Jan;22(2):229-37.

10 Hurwitz H, Fehrenbacher L, Novotny W, Cartwright T, Hainsworth J, Heim W et al. Bevacizumab plus irinotecan, fluorouracil, and leucovorin for metastatic colorectal cancer. N Engl J Med. 2004 Jun;350(23):2335-42.

11 Grothey A, Sugrue MM, Purdie DM, Dong W, Sargent D, Hedrick E et al. Bevacizumab beyond first progression is associated with prolonged overall survival in metastatic colorectal cancer: results from a large observational cohort study (BRiTE). J Clin Oncol. 2008 Nov;26(33):5326-34.

12 Chaft JE, Rusch V, Ginsberg MS, Paik PK, Finley DJ, Kris MG et al. Phase II trial of neoadjuvant bevacizumab plus chemotherapy and adjuvant bevacizumab in patients with resectable nonsquamous non-small-cell lung cancers. J Thorac Oncol. 2013 Aug;8(8):1084-90. 


\section{Case Reports in Oncology}

Nakagiri et al.: Surgical Treatment following Chemo-Targeted Therapy with Bevacizumab for Lung Metastasis from Colorectal Carcinoma

13 Liu CY, Hsu PK, Huang CS, Sun YH, Wu YC, Hsu WH. Chylothorax complicating video-assisted thoracoscopic surgery for non-small cell lung cancer. World J Surg. 2014 Nov;38(11):2875-81.

14 Isowa N, Hasegawa S, Bando T, Wada H. Preoperative risk factors for prolonged air leak following lobectomy or segmentectomy for primary lung cancer. Eur J Cardiothorac Surg. 2002 May;21(5):951.

15 Lastoria S, Piccirillo MC, Caracò C, Nasti G, Aloj L, Arrichiello C et al. Early PET/CT scan is more effective than RECIST in predicting outcome of patients with liver metastases from colorectal cancer treated with preoperative chemotherapy plus bevacizumab. J Nucl Med. 2013 Dec;54(12):2062-9.
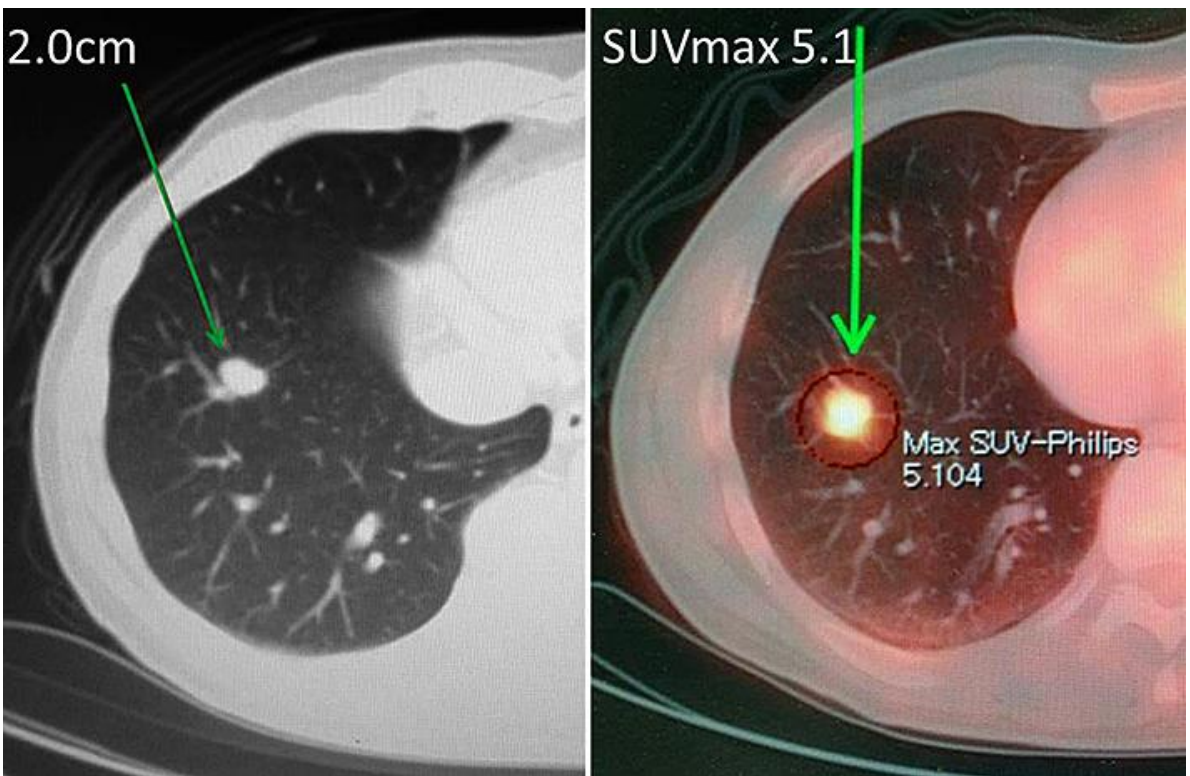

Fig. 1. Case 1. Pre-chemotherapy imaging findings. The tumor was $2 \mathrm{~cm}$ in size (left) and had a maximum standardized uptake value (SUVmax) of 5.1 in positron emission tomography findings (right). 


\section{Case Reports in Oncology}
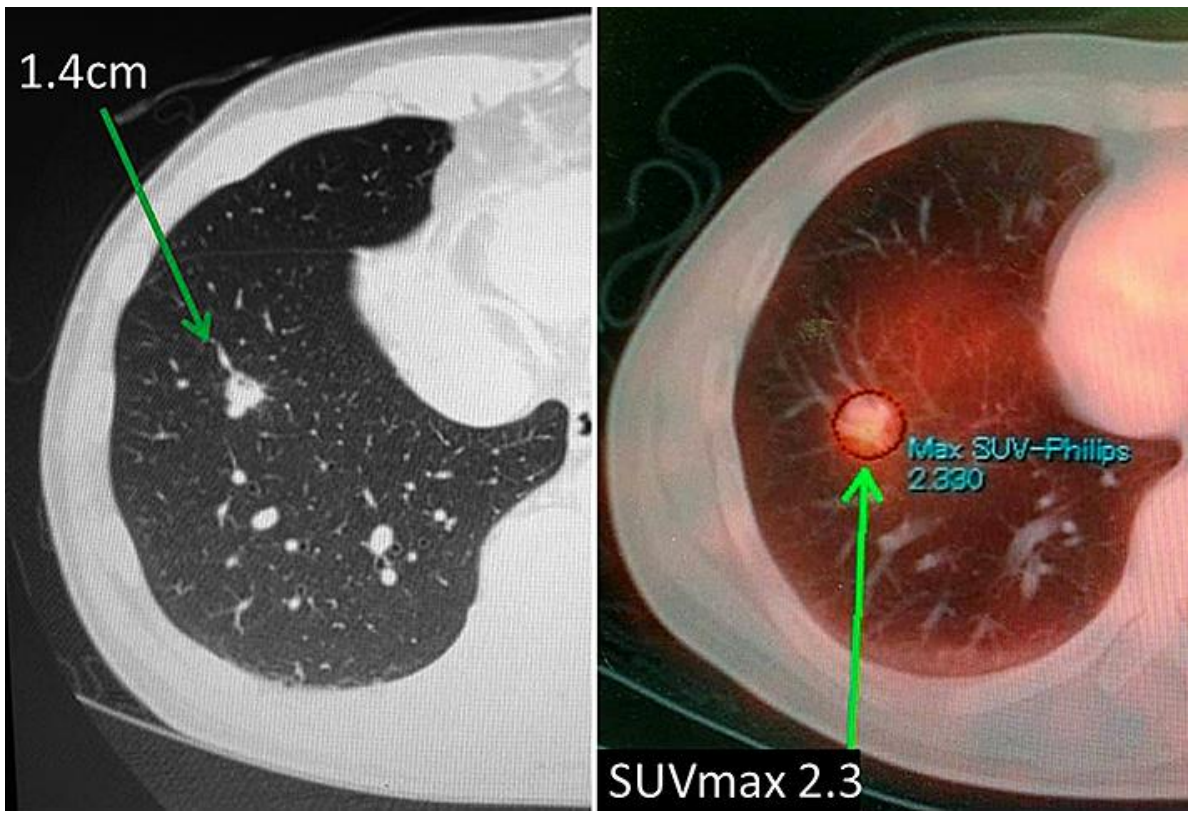

Fig. 2. Case 1. Computed tomography findings showed partial response. Following chemotherapy, the maximum standardized uptake value (SUVmax) value was 2.3.

Table 1. Patient characteristics $(n=11)$

Age, years

Gender (male/female)

Original lesions (colon/rectum)

Original colorectal carcinoma stage (I/II/III/IV)

Timing of lung metastasis (simultaneous/metachronous)

Indication of chemo-targeted therapy (induction therapy/ salvage therapy/new lesion)

Disease-free period, months

Laterality of lesions (right/left/bilateral)

Period from end of chemotherapy to operation, months

Effect of treatment (CR/PR/SD/PD)
$66.1 \pm 10.0$
$3 / 8$
3/8 (Rb: 6)
$1 / 3 / 3 / 4$
$1 / 10$
$5 / 3 / 3$
$22.5(0-58)$
$4 / 4 / 3$
$2.73 \pm 0.94$
$0 / 2 / 3 / 6$

Values are shown as numbers, mean \pm standard deviation, or median (range). CR, complete remission; PR, partial remission; SD, stable disease; PD, progressive disease. 
Nakagiri et al.: Surgical Treatment following Chemo-Targeted Therapy with Bevacizumab for Lung Metastasis from Colorectal Carcinoma

Table 2. Patient characteristics classified by indication for chemo-targeted therapy

\begin{tabular}{|c|c|c|c|c|c|c|c|c|c|}
\hline & Age, years & Sex & $\begin{array}{l}\text { Original } \\
\text { lesion }\end{array}$ & $\begin{array}{l}\text { Primary } \\
\text { pStage }\end{array}$ & $\begin{array}{l}\text { Disease-free } \\
\text { period after } \\
\text { primary operation, } \\
\text { months }\end{array}$ & $\begin{array}{l}\text { Size of the } \\
\text { largest } \\
\text { tumor, mm }\end{array}$ & $\begin{array}{l}\text { First chemo- } \\
\text { targeted therapy }\end{array}$ & $\begin{array}{l}\text { Second chemo- } \\
\text { targeted therapy }\end{array}$ & $\begin{array}{l}\text { Effect of } \\
\text { chemo- } \\
\text { targeted } \\
\text { therapy }\end{array}$ \\
\hline \multirow[t]{5}{*}{ Induction } & 75 & $\mathrm{~F}$ & $\mathrm{~A}$ & IV & 0 & 12 & CapeOX + bev & - & SD \\
\hline & 51 & M & Rs & IIIA & 55 & 15 & CapeOX + bev & - & PR \\
\hline & 69 & $\mathrm{~F}$ & $\mathrm{Rb}$ & IIA & 39 & 28 & CapeOX + bev & - & SD \\
\hline & 67 & M & $\mathrm{Ra}$ & IV & 0 & 25 & CapeOX + bev & - & PD \\
\hline & $76^{a}$ & $\mathrm{~F}$ & $\mathrm{Rb}$ & IIA & $0^{c}$ & 33 & FOLFOX & FOLFIRI + bev & PD \\
\hline \multirow{6}{*}{$\begin{array}{l}\text { Salvage } \\
\text { and new } \\
\text { lesion }\end{array}$} & $67 \mathrm{~b}$ & $\mathrm{~F}$ & $\mathrm{Rb}$ & IIIC & 24 & 12 & FOLFOX & FOLFIRI + bev & PR \\
\hline & 51 & M & $\mathrm{Rb}$ & IV & $13^{d}$ & 15 & CapeOX & FOLFIRI + bev & PD \\
\hline & 76 & $\mathrm{~F}$ & A & IIA & 30 & 10 & CapeOX + bev & - & SD \\
\hline & 73 & $\mathrm{~F}$ & $\mathrm{D}$ & IV & $11^{\mathrm{e}}$ & - & FOLFOX & FOLFIRI + bev & PD \\
\hline & 70 & $\mathrm{~F}$ & $\mathrm{Rb}$ & IIIA & 58 & - & CapeOX & FOLFIRI + bev & PD \\
\hline & 52 & $\mathrm{~F}$ & $\mathrm{Rb}$ & $\mathrm{I}$ & 17 & - & CapeOX + bev & - & PD \\
\hline Mean \pm SD & \multicolumn{4}{|l|}{$66.1 \pm 10.0$} & \multicolumn{5}{|l|}{$22.5 \pm 19.3$} \\
\hline \multicolumn{10}{|l|}{ Continued } \\
\hline & \multicolumn{2}{|l|}{$\begin{array}{l}\text { Period from } \\
\text { end of chemo- } \\
\text { targeted therapy } \\
\text { to operation, } \\
\text { months }\end{array}$} & $\begin{array}{l}\text { Operation } \\
\text { mode }\end{array}$ & $\begin{array}{l}\text { Number of } \\
\text { lung metastases } \\
\text { before lung } \\
\text { resection }\end{array}$ & $\begin{array}{l}\text { Histological } \\
\text { effects }\end{array}$ & $\begin{array}{l}\text { Disease-free } \\
\text { period after } \\
\text { lung resection, } \\
\text { months }\end{array}$ & $\begin{array}{l}\text { Area of recurrence } \\
\text { after lung } \\
\text { metastasectomy }\end{array}$ & $\begin{array}{l}\text { Survival } \\
\text { after lung } \\
\text { operation, } \\
\text { months }\end{array}$ & Outcome \\
\hline \multirow[t]{5}{*}{ Induction } & 2.2 & & Seg & 4 & $1 \mathrm{a}(1 \mathrm{a}, 1 \mathrm{a})^{\mathrm{g}}$ & 5 & Brain & 15 & Alive \\
\hline & 2.0 & \multicolumn{2}{|r|}{ Per } & 1 & $1 \mathrm{a}$ & 12 & Lung & 32 & Alive \\
\hline & 3.3 & \multicolumn{2}{|r|}{ Per } & 3 & $1 \mathrm{~b}(3,1 \mathrm{a})^{\mathrm{h}}$ & 11 & Brain & 18 & Alive \\
\hline & 3.1 & \multicolumn{2}{|r|}{ Seg } & 3 & $1 \mathrm{a}$ & 6 & Brain & 27 & Alive \\
\hline & 2.9 & \multicolumn{2}{|r|}{ Lob } & 3 & $1 \mathrm{a}$ & 22 & No recurrence & 33 & Alive \\
\hline \multirow{6}{*}{$\begin{array}{l}\text { Salvage } \\
\text { and new } \\
\text { lesion }\end{array}$} & 1.3 & \multicolumn{2}{|r|}{ Per } & 2 & $1 \mathrm{a}$ & 9 & Multiple metastasis & 30 & Dead \\
\hline & 1.2 & \multicolumn{2}{|r|}{ Per } & 1 & $1 \mathrm{a}$ & 6 & Multiple metastasis & 12 & Dead \\
\hline & 3.1 & \multicolumn{2}{|r|}{ Per } & 2 & $1 \mathrm{a}(1 \mathrm{a}, 1 \mathrm{a})^{\mathrm{g}}$ & 10 & Brain & 18 & Alive \\
\hline & 3.6 & \multicolumn{2}{|r|}{ Per } & 1 & $1 \mathrm{a}$ & 4 & Multiple metastasis & 49 & Dead \\
\hline & 3.8 & \multicolumn{2}{|r|}{ Per } & 1 & $1 \mathrm{~b}$ & 9 & No recurrence & 25 & Alive \\
\hline & 3.7 & \multicolumn{2}{|r|}{ Per } & 1 & $1 \mathrm{a}$ & 6 & Lung & 12 & Alive \\
\hline Mean \pm SD & $2.73 \pm 0.94$ & & & & & $10.9 \%^{\mathrm{i}}$ & & $68.2 \%$ & \\
\hline
\end{tabular}

PD, progressive disease; SD, stable disease; PR, partial response; Seg, segmentectomy; Per, partial resection; Lob, lobectomy.

${ }^{a}$ Chylothorax. ${ }^{b}$ Prolonged air leakage. ${ }^{c}$ Recurrence found during hospitalization. ${ }^{d}$ Liver metastasectomy simultaneously performed. ${ }^{\mathrm{e}}$ Liver metastasectomy and peritoneal resection of direct invasion simultaneously performed. ${ }^{\mathrm{f}}$ All the tumors were resected using a metastasectomy procedure. $\mathrm{g}$ Bilateral lung metastasectomy simultaneously performed. ${ }^{\mathrm{h}}$ Bilateral lung metastasectomy performed in a metachronous manner. ${ }^{\mathrm{i}}$ 5-year disease free survival rate. ${ }^{j}$-year survival rate. 


\section{Case Reports in Oncology}

Table 3. Perioperative results (11 cases, 14 lesions)

Operation mode

(partial resection/segmentectomy/lobectomy)

Operation time (median, range), min

Blood loss (median, range), $\mathrm{mL}$

Postoperative hospital stay (median, range), days

Perioperative complications

Chylothorax

Prolonged air leakage

Histopathological effects $(n=14,1 \mathrm{a} / 1 \mathrm{~b} / 2 \mathrm{a} / 2 \mathrm{~b} / 3)$
$8 / 2 / 1$

$75(53-180)$

$10(5-230)$

$8(5-23)$

1

1

$13 / 1 / 0 / 0 / 1$ 